\title{
"This Maths is better than that Maths" - Exploring Learner Perceptions on the Integration of History of Mathematics in Teaching the Theorem of Pythagoras: A Case Study
}

\author{
Lifeas Kudakwashe Kapofu ${ }^{1 *}$, Winfilda Kapofu ${ }^{2}$
}

\author{
${ }^{7}$ Department of Education Australia, AUSTRALIA \\ 2 Durban Girls' Secondary School, SOUTH AFRICA \\ *CORRESPONDENCE: $\square$ lifeask@yahoo.co.uk
}

\begin{abstract}
Integration of history of mathematics (HOM) in mathematics education is emerging as frontier endowed with utility to stem decline in uptake, enhance performance and alter the negative perceptions about the subject. This case study sought to explore the influence of history of mathematics on grade eleven girls' perceptions of the Theorem of Pythagoras in particular and mathematics in general. In this exploratory study, the genetic approach of HOM was used in teaching the Theorem of Pythagoras. Findings indicate that the inclusion of aspects of the history of mathematics catalysed positive learner perceptions of the Theorem and mathematics in general. Notable changes in learner perceptions included affirmations of an increased level of motivation and confessed improvement in readiness of grade eleven learners in tackling challenging tasks involving the Theorem of Pythagoras. Learners also alluded to increased confidence in dealing with proofs, enjoying making their own discoveries and solving mathematical problems in general.
\end{abstract}

Keywords: history of mathematics, Pythagoras Theorem, integration, learner perceptions, influence of history of mathematics

\section{INTRODUCTION}

The advent of the Fourth industrial revolution offers a backdrop characterised by unparalleled technological developments and innovations. This revolution is characterised by ubiquitous internet-based connectivity, artificial intelligence, smart manufacturing and smart factories. An imperative for this revolution is science and mathematics education and re-education. There is scholarly consensus that never has there been a greater need for special skills or STEM education to cope with the technological advances and capture value than now.

Despite the paradigm shift necessary for the Fourth industrial revolution, South Africa's mathematics education seems unresponsive. The status of mathematics education in South Africa is characterised by dwindling uptake of mathematics at FET (Torerai, 2013) which Radebe (2013) quantified as 25\% between 2011 and 2013 alone. Whilst focusing on the qualitative trends Barry (2014) notes a continuous decline in the quality of mathematics results despite having the pass mark at 30\%. Scholarly work tracking both quantitative and qualitative trends in mathematics education in South Africa paint a concerning picture (Barry, 2014; Naidoo \& Kapofu, 2020; Radebe, 2013; Torerai, 2013). According to these scholars, any purported increase in the national mathematics pass rate is largely a function attributable to reduced enrolments in the

Article History: Received 23 April $2020 \bullet$ Revised 31 May $2020 \bullet$ Accepted 4 July 2020

(C) 2020 by the authors; licensee Modestum. Open Access terms of the Creative Commons Attribution 4.0 International License (http://creativecommons.org/licenses/by/4.0/) apply. The license permits unrestricted use, distribution, and reproduction in any medium, on the condition that users give exact credit to the original author(s) and the source, provide a link to the Creative Commons license, and indicate if they made any changes. 
subject, which create an illusion of improvement in a context of academic decline. Whilst explaining the status quo vis-a-vis quantitative and qualitative trends the latter scholars attribute the downward spiral in mathematics uptake and results to waning learner interest. The prevalence of the above status quo in South African schools is not sustainable because its impacts permeate all facets of South African life. It threatens South Africa's capacity to build its human resources capital in mathematics related fields.

Another contributory factor identified by these scholars has been negative learner perceptions of the subject, which borders on phobic aversion of mathematics as a discipline. Whilst publicised national grade12 examination results are doing little to ameliorate the academic anxiety that is stifling both uptake and attainment, examination analytical and diagnostic reports attribute learner apprehension to limited conceptual understanding of mathematical fundamentals associated with learner perceptions of mathematics as difficult. The challenge presented by such a context is the amelioration of the fears and insecurities associated with the subject in South African high schools. This prevailing reality prompts research to explore opportunities for mitigation and generation of responsive transformative contexts. The latter contexts are expected to have dual utility, that of influencing learner perceptions towards the realisation of the power of mathematics and promoting learner active participation in pedagogic settings.

It is in the ambits of the possibility of the unfolding of this reality that research has to explore ways of mitigating academic decline in mathematics through promoting interest and throughput in mathematics. Clark (2019) posits this possibility of turning the tide through nurturing positive perceptions and attitudes towards the subject. The scholar's contention is that teaching processes in mathematics need to be postured towards the nurturing of positive perceptions and attitudes towards the subject as a precursor for sustainable content mastery. This study was a response to the realities of the challenges inherent in the contemporary context and heeding the call for sound practice. It was borne out of the need to explore the possibility in didactical innovations to positively impact learner perceptions of mathematical concepts like the Theorem of Pythagoras as an aspect of geometry.

Geometry is a pillar in mathematics and has been earmarked as a mathematics domain with unlimited potential to make the subject lively (Sinclair \& Bruce, 2015). Geometry straddles across disciplines such as culture, history, art and design. There is scholarly consensus that learning geometry enhances cognition and problem-solving abilities (Hanna, 1998). This attribute is captured in the South African curriculum policy documents such as Curriculum Assessment and Policy Statement (CAPS) as the centrality of the ability for clear logical thinking is centred. In this curriculum document it is envisaged that critical skills such as questioning, conjecturing, examination and experimentation can be promoted and enhanced by learning geometry (Department of Basic Education, 2014). It is envisaged that once learners have mastered these capabilities they can transfer them to other domains (Gonzalez and Herbst, 2006). Geometry is also regarded as an essential domain in mathematics because it has real-life applications through the use of shapes and construction abilities which can be deployed in novel situations. Scholars like Gonzalez and Herbst (2006) posit that geometry is one domain in mathematics that provides learners with the opportunity to relive the experiences of mathematicians through mathematical activities that are innovative and promote discovery learning. The notion is that geometry enhances learners' capacity to analyse three-dimensional shapes as well as their construction and interpretation of mathematical arguments. The reintroduction of Euclidean Geometry in the senior phase in South African schools attests to the importance and utility of geometry as a vehicle in the accomplishment of curriculum aspirations through mathematics education. Cognisant of the importance of geometry it is evident that geometry needs to be taught effectively and that learners like, learn and develop content mastery of geometrical content. To teach effectively there is need for teaching approaches that generate and sustain learner interest whilst encouraging logical thinking and problem-solving abilities. It is in the ambits of this need that HOM's utility in this regard was explored.

Research findings and emerging scholarly work is pointing to the integration of HOM as a vehicle imbued with the potential to stem learning creep and generate the passion for mathematics in high school learners. It was our persuasion that integration of HOM could dispel some phobia for geometry and circumvent insecurities associated with the uptake of mathematics as observed by Naidoo and Kapofu (2020). In the these scholars' research, findings were that grade eleven learners regarded geometry as difficult and confusing. As we undertook this study, we envisioned that the integration of HOM had the potential to influence learner perceptions towards the Theorem of Pythagoras as an important concept and circumspectly influence the quality of mathematics teaching and learning. 


\section{LITERATURE REVIEW}

A humanistic-cultural purview conceptualises mathematics as a human creation evolved over millennia in response to socio-economic needs and a science bound to man's socio-economic contexts (Kilpatrick, 2020). According to Clark, Kjeldsen, Schorcht and Tzanakis (2018) mathematics is man's intellectual endeavour grounded in history but situated in an ever-present reality. The historical locus of modern mathematics, related human activities and man's struggles for survival are captured in Hoyrup's (1994) study on Grecian metric system development. In Hoyrup's (1994) study mathematics is constituted as a discipline grounded in the annals of history whose understanding cannot be dissociated from understandings of the formal relations and social practices in which it is generated. The emerging understanding from the scholars above is that mathematical concepts are imbricated in the socio-historical systems, processes or procedures of their production with the latter driving revolutions in mathematical thought. In this dialectic Moretti and Radford (2016) contend that it is a didactic necessity for education to centre the studying of concepts in their process of production since human thinking is ontogenetically subsumed in cultural reality. It is in this dialectical conceptualisation of mathematical knowledge and historically nuanced human agency that the potential pedagogical utility of HOM lies. HOM has potential utility in activating learners' theoretical thinking and igniting their passion in contemporary classrooms through guided journeys into the historicity of target mathematical concepts.

Within South African education, the epistemological density of knowledge inherent in HOM is fully acknowledged and its enactment promoted. For example, the Revised National Curriculum Statement (RNCS, 2002 , p. 6) maintains "...the teaching and learning of mathematics can enable the learner to develop an awareness of the diverse historical, social and cultural practices of mathematics". RNCS (2005, p. 99) also gives the following as some of the grade 8 Assessment Standards, “...Describes and illustrates the historical and cultural developments of numbers. Describes and illustrates ways of measuring in different cultures throughout history (e.g. determining right angles using knotted string leading to the Theorem of Pythagoras)". These prescripts acknowledge the importance of HOM in the learning of mathematics. Currently, these norms are embedded in the Curriculum and Assessment Policy Statement (CAPS) through the promotion of HOM as a way of presenting mathematics as a human creation. To steer curriculum implementation towards this end, the body politic calls for assessment standards to include the need for learners to be able to describe and illustrate the historical and cultural developments of numbers. There is also a call for learners to describe and illustrate ways of measuring in different cultures throughout history, for example, determining right angles using knotted string leading to the Theorem of Pythagoras (Curriculum and Assessment Policy StatementCAPS, 2011).

Political aspirations have been translated in some curriculum materials that have made an obvious effort to include materials with historical flavour. For example, in Carter, Dunne, Morgan and Smuts (2006, p. 8) an illustration of the ancient Indian numerals used in the eastern part of the Arabic empire in the years between 969 and 1082 is given. Laridon (2006) on the other hand provides a summary of the origins of Pythagoras' theorem. However, personal observation has been that despite the robust socio-political framework and overtures in curriculum development there is little evidence of HOM being foregrounded in practice. This reality is taking place against background of a universal drive to harness the currency in HOM.

Though still in its formative stages as an epistemic entity, the utility of history of mathematics (HOM) in mathematics education is not a new phenomenon. Literary works as far as the last quarter of the nineteenth century attest to the value of HOM in teacher education (Furinghetti \& Radford, 2002). The world over the importance and role of HOM in mathematics education is acknowledged by international professional councils such as the National Council of Teachers of Mathematics (NCTM) in the United States of America. Research in mathematics education affirms the centrality of HOM (Bütüner \& Baki, 2020; Furinghetti, 2000; Goktepe \& Ozdemir, 2013; Horton \& Panasuk, 2013; Siu, 2004). Key findings in this scholarly work point to the utility of HOM in learner mathematics-schema development; its capacity in providing for open-mindedness and flexibility in resolving mathematical problems (Furinghetti, 2000). From their research, Horton and Panasuk (2013) posit the rich endowment of HOM, for a solid buttressing in mathematical comprehension and conceptual development. The researchers concluded that HOM provides learners with opportunities for experiential learning through packaging mathematics as human endeavour rather than an island that is “...closed, dead, emotionless and all discovered..." (Bidwell, 1993, p. 461). Scholarly contention is that a possibility exists in HOM to shunt pedagogic settings from these islands to the mainland of interesting mathematics. The seminal works of Cajori (1894) and Freudenthal (2006) affirm the affective and scaffolding value of HOM in teacher education. The working group for the History and Pedagogy of Mathematics (1972) 
and the International Study Group on the relations between History and Pedagogy of Mathematics (1976) attest to the serious transformative potential in HOM (Furinghetti, 2007). Such promising findings have pushed HOM epistemological boundaries further as scholars explore its pedagogical potential and didactical utility (Jankvist, 2009; Goktepe \& Ozdemir, 2013; Karp, 2014; Horton \& Panasul, 2013).

It is within the context of potency and utility that scholarly work is advocating a paradigm shift from using the history of mathematics to integrating history of mathematics (Siu \& Tzanakis, (2004). The contention in this advocacy is that HOM and mathematics as disciplines are inseparable. Whilst exploring the potency of HOM as a pedagogical tool, Horton and Panasuk (2013) argue against the teaching of mathematics as a dehumanised isolate by hedging it from its history. The scholars opine that such a hedged context negates the origins of mathematics. Clark et al. (2018), forward five ways in which HOM has potency. HOM has the potential to enhance the mastery of mathematical concepts; develop an appreciation of mathematics and mathematical activity; capacitate teachers didactically and enrich their pedagogical repertoire; re-brand mathematics as a volitional human endeavour and appeal to the domain of affect hence motivation. What is notable from research above is that HOM has potential in influencing objective output. However, this study sought to explore its influence if any in the domain of affect. Thus, placing this study in the realm of this scholarly work involved exploring whether the HOM particularly the history of the Theorem of Pythagoras would influence learner perceptions and if so how it influenced these perceptions.

The symbiosis between learners' perceptions of mathematics and their learning of mathematics has been widely acknowledged (Hartley \& Treagust, 2014; Pehkonen \& Torner, 1998; Schoenfeld, 1992). Perceptions in this study are conceptualised as dynamic affective activities that include opinions built from experiences, feelings, values and processes that deal with emotions (Entwistle \& Smith, 2002). Rooted in constructivism is the notion that learners bring their own ideas to a mathematics lesson. The latter are built from, socially shared mathematical experiences, context-bound shared mathematical experiences and previous mathematical experiences (Van de Walle, 2004). Perceptions are important because they shape enactments. As acknowledged by Torerai (2013) fewer learners choose mathematics at grade 10 opting for mathematical literacy that they perceive as less difficult. Other than influencing uptake perceptions also influence one's performance in mathematics (Pehkonen \& Torner, 1998). Learner beliefs built on mathematical perceptions are important for they form the frame for an individual's knowledge structure. Thus, perceptions create a frame that broadly influences each individual's mathematical understanding.

\section{CONCEPTUAL FRAMEWORK}

Cognisant of the myriad ways for HOM integration in mathematics education framing is a research necessity. Framing of history, historical knowledge hence HOM as conceptualised in this study is within Collingwood and Collingwood (1994) characterisation of historical knowledge. Collingwood and Collingwood (1994) posit:

Historical knowledge is the knowledge of what the mind has done in the past, and at the same time, it is the redoing of this, the perpetuation of past acts in the present. Its object is therefore not a mere object, something outside the mind which knows it; it is an activity of thought, which can be known only insofar as the knowing mind re-enacts it and knows itself as so doing. To the historian, the activities whose history he is studying are not spectacles to be watched, but experiences to be lived through in his own mind; they are objective, or known to him, only because they are also subjective, or activities of his own (p.218).

Several theoretical strands with implications for education emerge as Collingwood and Collingwood positing is juxtaposed with education. The primary strand is that, links between past and current knowledge exist and the educational enterprise should not only focus on informing learners of current discourse or how things are executed but should also nurture learner cognition through the promotion of self-awareness as capable beings who are functionaries of a complex reality. Thus, with Collingwood and Collingwood understandings, education in general and mathematics education in particular is a mosaic of the objective, subjective and enacted in a way that aligns the pedagogic settings with the terminal outcomes of general education whilst attendant to critical targeted concepts and enactments.

The second strand crucial in conceptualising HOM integration and with utility for this study is the importance of agentic enactment in the acquisition of knowledge. For Collingwood and Collingwood, life and 
living are exploratory and human actions are located in a historical and ideological reality. Cognisant of this locus, agentic actions and activities are critical in knowledge acquisition. As enunciated by Fried, Guillemette and Jahnke (2016, p. 224) "it is in the concrete action that the historical movement is created". Implicit in this notion is the view that pedagogic settings that acknowledge the utility of HOM should provide opportunities for learners to actively engage with artefacts of the culture whose knowledge they intend to acquire. According to Collingwood and Collingwood (1994) enactments of the past in the present create or recreate the very essence of socio-historical reality. During historical re-enactments, learners experience intellectual disorientation through the shock of being immersed in another culture. Fried et al. (2016) contend that it is in the intellectual astonishment and disorientation that arises as learners' shuttle between the past and the present that movement towards self-knowledge emerges which prompts learners to reconstitute and reidentify themselves as mathematical beings.

The last strand emerging from Collingwood and Collingwood (1994) characterisation that has a bearing on HOM integration in mathematics education is the centrality of dialogue. Dialogue has transactional duality, that is, dialogue with self and dialogue with others. The former is associated with intellectual astonishment with learners introspecting, confronting and reflecting on their own conceptions as they search for meaning in the face of foreign meaning. Dialogue with others is premised on the notion that knowledge generation is a human endeavour since humans are social beings. History therefore is "a place to enter into dialogue with others and with the historical conceptual products produced by the cognitive activity of those who have preceded us in the always-changing life of cultures" (Radford, Furinghetti \& Katz, 2007, p. 109). The educational context envisaged in this conceptualisation is one in which learners are not private owners of knowledge but active ethical agents involved in epistemic overtures in cultural milieus. The lived experience in such a context is one of otherness in mathematics. Such an experience "focuses not necessarily and exclusively on the relation to ourselves, but more broadly, on a relation with the Other in mathematics, a movement toward the community" (Fried et al., 2016, p. 225).

The above three strands of thought framed this study and provided the thinking tools that undergirded the decisions and choices made in this study. However, the approach to integrate HOM in this study Collingwood and Collingwood (1994) thinking tools resonate with the genetic approach. The genetic approach is a teaching strategy inspired implicitly or explicitly by HOM and aims at dispensing mathematical concepts, processes and procedures. Framed within the genetic approach classroom presentations are devoid of or have superficial historical material but are constructed to facilitate an analytical exploration of the historical progression of mathematical thought (De Villiers, 2008). This approach posits that individuals acquire mathematical knowledge in the same way in which humanity developed it (Polya, 1963; Freudenthal, 2006), that is, through discovery or invention. The overall spirit of the genetic approach is reconstructive. The genetic approach propositions that mathematical content should not be presented to learners as a polished terminal product of mathematical engagement, but rather the content should be re-constructively packaged during teaching and learning. Within the context of the genetic approach, instruction needs structuring in ways that subject learners to the experiences that their forerunners underwent as they grappled with inventing mathematical theorems, axioms, concepts and algorithms.

\section{PURPOSE OF THE STUDY}

The work presented in this article is part of a bi-pronged project whose first part involved exploration of learner perceptions of mathematics in general and geometry in particular. This first part explored learners' perceptions of learning geometry in Grade 11. Through two focus group interviews and thirty personal journal entries learners' perceptions of geometry were solicited. The questions in the focus groups were designed to tease participants views and perceptions of learning geometry. Such questions included: What are your perceptions of learning geometry in Grade 11? What are some of your experiences of learning geometry in Grade 11? Personal journals were used to capture learner experiences of learning Grade 11 geometry. Over one school term learners wrote their experiences and perceptions. Findings from the first part the project were that learners found mathematics to be difficult and confusing as well as demanding and time-consuming. Majority learners perceived geometry to be difficult and confusing as well. They also perceived geometry to be stressful and all about proofs. However, the first part of the study found that learners perceived mathematics as interesting if teaching was to involve concrete manipulatives. Cognisant of the findings highlighted, the second part of the project sought to explore the influence of integrating HOM in teaching geometry. The influence of HOM was to be assessed vis-à-vis learner perceptions after they had been exposed to instruction in which HOM had been integrated. The second part of this project is the study referenced in this article. This study 
sought to capture learner perceptions after the integration of History of Mathematics in teaching the Theorem of Pythagoras.

\section{Research Questions}

The following research question informed the second part of the project and guided this study:

What are learner perceptions of the lessons on the Theorem of Pythagoras after the integration of History of Mathematics?

\section{METHODOLOGY}

This study foregrounded qualitative data in pursuit of knowledge (Kaplan \& Maxwell, 1994). Framed by Collingwood and Collingwood thinking tools this study's methodology upheld three basic assumptions. The first assumption being that when trying to decipher and interpret human phenomena, things are best studied in their natural settings (Denzin \& Lincoln, 2005). The second assumption was that knowledge is a social construct as active self-determining individuals become involved in the research process (Schwandt, 2000). Hence, in this study it became our belief that the best people to inform us about the phenomenon under study were the learners themselves. The third assumption was that researchers as one of the Others and members of the classroom community needed to strive to get the insiders' perspective and interpretation of experiences (Schwandt, 2000). Heeding and embracing these assumptions this study became an endeavour to explore the complex world of the lived experiences of grade eleven learners and amplify their voice as they learnt mathematics.

\section{Participants}

This study was conducted at Warrenview Girls High School (WGHS)*. Warrenview Girls' high school is a multicultural institution of almost one thousand girls located in a coastal resort city in South Africa. Participants in this study were all the thirty learners that made up the single mathematics at WGHS.

\section{Ethical Considerations}

Giving due credence to ethical considerations permission to conduct this research was sought and granted by all relevant gatekeepers which were the Department of Education KwaZulu-Natal, The School Principal and the School Governing Body. By virtue of the participants being minors the parents / guardians of participants (Cohen, Manion, \& Morrison, 2013) signed consent forms. Anonymity was maintained through the use of pseudonyms and the location of the research site was also not disclosed in the study.

\section{Data Collection}

To generate the qualitative data to answer the research question two data collection techniques were employed. These included group interviews and journal entries.

Data was collected using learners' journal entries, which all the thirty learners kept for the entire duration of data collection in this study. Learners were encouraged to write what they felt, thought and experienced in the mathematics lessons in their journals. This approach was used to obtain perceptions on the theorem of Pythagoras from all learners and not necessarily those who were to constitute the focus groups. It was our view that the influence of the history of mathematics on learner perceptions could be gleaned from learners' documented experiences and opinions since some learners may have been shy or uncomfortable to critique the teaching method during the focus interviews. The journals entries were also utilised periodically (after set of tasks), as a reflexive tool by the researchers to inform further prompting in focus groups. Learner journals were collected and entries were transcribed and analysed during data analysis.

Learners' perspectives and perceptions on Pythagoras' Theorem were solicited through focus groups that were conducted with two groups of eight randomly selected learners from the grade eleven mathematics class (Fox, Hunn \& Mathers, 2002) over two school terms. Other than the richness of data generated through this method, it was also convenient and quick (Cohen, Manion \& Morrison 2013). Engagement in focus groups was poised at exploring learner perceptions verbatim and was guided by a peer-reviewed schedule with semistructured and open-ended questions. Further probing intermittently enabled free-flowing conversations in the focus groups and generated deeper insights. All data collected during group interviews was video-recorded and transcribed. 


\section{Data Analysis}

Informed by the conceptual framework data analysis involved categorisation and node formulation. Categorisation involved excavation of complex threads of the data in search of similarities and categorising according to similarities. Analysis of categories yielded thematic nodes that were developed using NVivo 10 software programme. The emergent nodes included learner perceptions of geometry; learner perceptions of Pythagoras' Theorem and learner perceptions of HOM integration.

\section{FINDINGS}

HOM integration in mathematics lessons was done over two school terms in a grade eleven class at Warrenview Girls High School. HOM was used in designing of learning activities and cascading the knowledge on the Pythagorean Theorem, its proofs and various applications.

\section{Learners' Perceptions on HOM Integration in the Use of Historical Narratives}

The integration of HOM in the lessons on the Theorem of Pythagoras involved the use of historical narratives on Bhaskara, Pythagoras and several other mathematicians who proved that the theorem holds. This method seemed well received by the majority of grade 11 learners at WGHS as evidenced in their reflections in their journals. It seemed the inclusion of HOM positively impacted learner' perceptions of geometry and the Theorem of Pythagoras itself. According to the learners, the use of narratives from the history of the Theorem of Pythagoras made the lessons very exciting and informative. For example Lorraine's remarks with reference to the story of Bhaskara, his life, achievements and his family:

\section{"Very interesting to find out about Bhaskara and his daughter..." (Group Interview, 20 th of August).}

Such a remark humanised the subject an aspect which was found missing when learner perspectives where solicited in contexts where HOM had not been integrated (Naidoo \& Kapofu, 2020). With the inclusion of HOM, the theorem was rendered a human face with real human beings and learners ceased to see it as a cold hard science and a curricula isolate. This purview was also affirmed by Phumla who posited in her journal that,

"The lesson was good and exciting and it changed the way we look at things. We learnt about the mathematician Bhaskara which we did not know so it was good to know it for the first time..." (Journal Entry, 15 ${ }^{\text {th }}$ of August).

For Sbu the lesson was:

“...quite interesting because I learnt that mathematics is not only about numbers... it was quite interesting to learn about the history of Pythagoras' Theorem.” (Group Interview, 20th of August).

Learning about the mathematicians who invented theorems and axioms made learning exciting for the learners as well as changed their perception of the Theorem of Pythagoras. It was our finding that the history of the Theorem of Pythagoras awakened in the learners a desire to know more. Sarah thought that the same lesson was interesting as she had learnt about the mathematician Bhaskara and expressed that the lesson had left her in suspense such that she wished to read more about the story of Bhaskara and his work (Journal Entry, $5^{\text {th }}$ of August). Sarah's intimation indicated that through HOM integration the quest for learning in some learners had been re-ignited.

The method of using stories fascinated most of the learners because they had not thought of mathematics as having a theoretical or non-numerical aspect or background to it. For them, it had always been presented as a finished product devoid of any human elements. Humanising mathematics through HOM integration seemed to produce excitement that appealed to the domain of affect wherein it triggered intrinsic motivation. In Figure 1, learners engage in work involving Bhaskara's proof and a story of his life.

Other than functioning solely as motivation tools the stories about the mathematicians, their lives, pursuits and achievements seemed to have impacted on learner preparedness to work. From the sentiments posited by the learners, it was found that the hardships, hard work and accomplishments of the mathematicians the learners researched on and learnt about, helped learners change their perception of working through the Pythagoras' Theorem and geometry. Nolwazi reminisced, "The research she had 


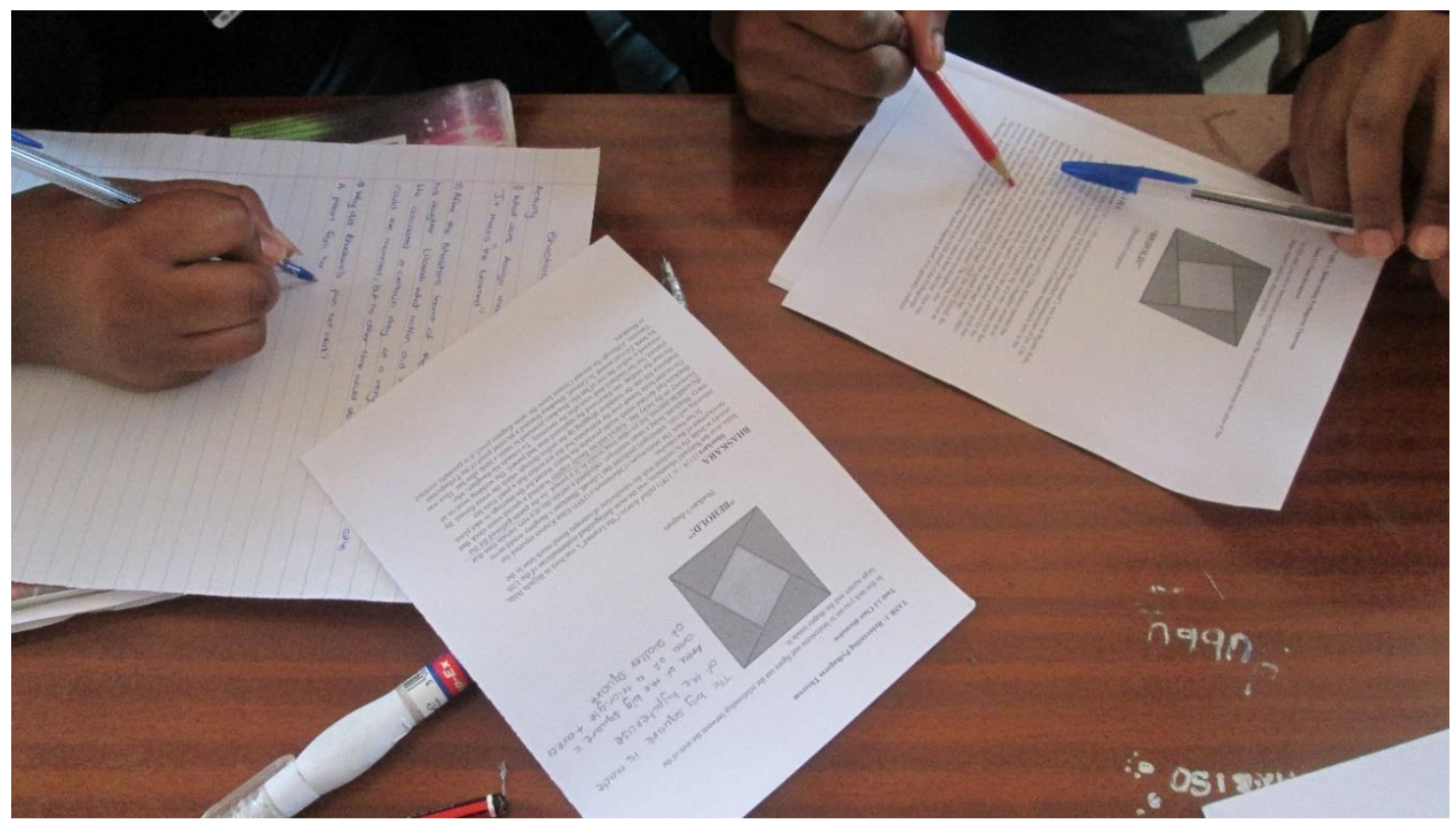

Figure 1. A learning activity on Bhaskara's diagram and some literature about his life

conducted on Descartes had encouraged her to persevere even though she was faced with challenges and difficulties in mathematics and in real life" (Focus Group, $3^{\text {rd }}$ of September). Nolwazi was a sickly child and identified with Descartes easily and felt challenged by his determination. Reflecting on her research of Euclid Lorraine claimed, "Euclid's work gave her inspiration to persevere and do her best" (Group Interview, $3^{\text {rd }}$ of September). In the same Focus Group, Maxine who had studied Mary Mirzakhani, remarked, "Maryam Mirzakhani really showed me that through hard work and perseverance you can achieve a whole lot more."

Through their experiences with the history of mathematics as historical narratives, learners felt that their struggles were not unique to them an aspect which seemed have the effect of reducing their anxieties when presented with mathematics problems.

Inclusion of the history of mathematics led learners to develop not only an appreciation of hard work and its benefits but also that mathematical greatness is not achieved in one day, for one has to work for prolonged periods to improve and perfect one's mathematical skills. Through interpretation of historical narratives, learners were of the view that they had learnt to be patient with and not to be too hard on themselves when solving mathematical problems as intimated by Phume (Group Interview, $3^{\text {rd }}$ of September),

mathematical concepts require time, they cannot be mastered over a single activity but through consistent hard work since the mathematicians themselves took years to accomplish the mathematical theorems, axioms and postulates that are in use today (Group Interview, $3^{\text {rd }}$ of September).

These findings affirm the view that inclusion of HOM fostered a positive attitude towards the subject. Embracing a positive attitude led learners to profess an appreciation of the qualities associated with the subject such as great work ethic whilst imputing genuine enjoyment into mathematics.

\section{Learners' Perceptions of HOM Integration as Discovery Learning}

HOM integration through the genetic approach also involved the use of discovery learning. As prescribed by the genetic approach discovery learning involved learners deriving the Pythagorean Theorem. HOM integration in this regard entailed learners applying their problem solving skills in logically creating sound proofs of the theorem. After lessons in which they managed create sound proofs, Ayanda reminisced HOM had helped her"... understand the roots of what I am doing because we sometimes ask ourselves this question - why do we have to apply Pythagoras' Theorem?" (Group Interview, 3 ${ }^{\text {rd }}$ of September). In her journal entry Nonhlanhla posited that HOM inclusion as discovery learning was"...interesting, as I usually learn to use the theorems not actually proving or looking at how they were invented" (Journal Entry $28^{\text {th }}$ of July). What emerged 
from these remarks was that HOM integration scaffolded learner conceptualisation of mathematical concepts for the majority of the learners.

Not only did HOM integration facilitate conceptualisation, it also democratised the pedagogic setting as it devolved the power to learn to the learners. Expressing appreciation of HOM infusion through discovery learning Jackie documented that:

"The teacher lets us do the work ourselves rather than just feeding us on information. The method she used made it fun for us to understand what we were learning." (Journal Entry, $28^{\text {th }}$ July).

Phume like Jackie preferred this method because:

She lets us do the work without her input and we liked it because there were no rules she gave us on how to answer the question so we did the work according to our understanding..." (Journal Entry, 28 $8^{\text {th }}$ of July).

For Ayanda discovering the Theorem of Pythagoras:

"...was very interesting and challenging like we said before that maths, you find maths quite frustrating so this time, being able to do it by ourselves, on our own, it was like a victory, like you have won a battle...you could do it yourself, you could prove it right without actually getting frustrated, being stressed trying to figure out a way forward." (Focus Group 5 ${ }^{\text {th }}$ August).

Nozipho, who had not invented or proved the Theorem of Pythagoras before expressed her enthusiasm at having re-discovered the theorem for herself, "I really learnt something very good because I didn't know how the Pythagoras' Theorem came about." (Journal Entry, $5^{\text {th }}$ of August). Sammy perceived HOM inclusion as a mathematical renaissance as she likened lessons as, "mind awakening..." (Journal Entry, $5^{\text {th }}$ of August) and provided them the opportunity think "outside the box" (Pretty, Focus Group, $5^{\text {th }}$ August) an aspect which she thought was important in understanding mathematics and other subjects. Learners opined that HOM infusion packaged as discovery learning challenged their thinking capabilities and made them exercise their minds. Thus, HOM encouraged flexibility and open mindedness when dealing with mathematical problems.

\section{Learners' Perceptions of HOM Integration as Co-operative Learning}

Another aspect of HOM espoused by the genetic approach is co-operative learning. Investigation of the influence of HOM on learner experiences also investigated the deployment of cooperative learning in the designing and the teaching activities of the Pythagoras Theorem. Cooperative learning involved group tasks, working in pairs as well as participating in class discussions.

Group activities involved paper cutting to produce various shapes as well as working through mathematical tasks as a collective. Learner experience with group activities was positive. For the paper cutting activities, the benefit had the duality of camaraderie as well as psychomotor enactment. Phume's journal entry (Focus group $28^{\text {th }}$ of July) captured this duality”...the lesson was fun and realistic because we were using objects we can see and we were doing our work all by ourselves, interesting because we were proving what we did, on our own, working together." Concurring Maxine in the same focus group remarked, "I liked using my hands, so I enjoyed it." She regarded the same lesson as "awesome" because "We got to cut and compare shapes." Samke (Journal Entry, $5^{\text {th }}$ of August) further elaborated "The lesson was fun because we got to cut shapes out and figure out how they connect to each other and we got to see things about shapes that I did not know." Figures 2 and 3 show learners engaged in cooperative learning.

The dominant common thread that traversed learner experiences after exposure to HOM was that they found working in groups enjoyable with multiple benefits. Most learners concurred that cooperation in class activities created a platform for them to share ideas in a comfortable environment. In her journal entry, Jackie opined that, "The method used made it fun for us to understand what we were learning... we worked in groups and we were all part of what was being taught for the day." (Journal Entry, $25^{\text {th }}$ of July). Confirming similar HOM influence Wendy intimated, "The lesson was fun and all of us as learners participated in the lesson and helped one another by sharing ideas..." (Journal Entry, $5^{\text {th }}$ of August). Learners also claimed integration of HOM in this manner provided a platform for discussion of their understanding of the targeted tasks and for the validation of their ideas before they put pen to paper in response to the questions assigned. Learners were of the view that HOM integration simplified learning as intimated by Feryn, “...group work makes it easier for 


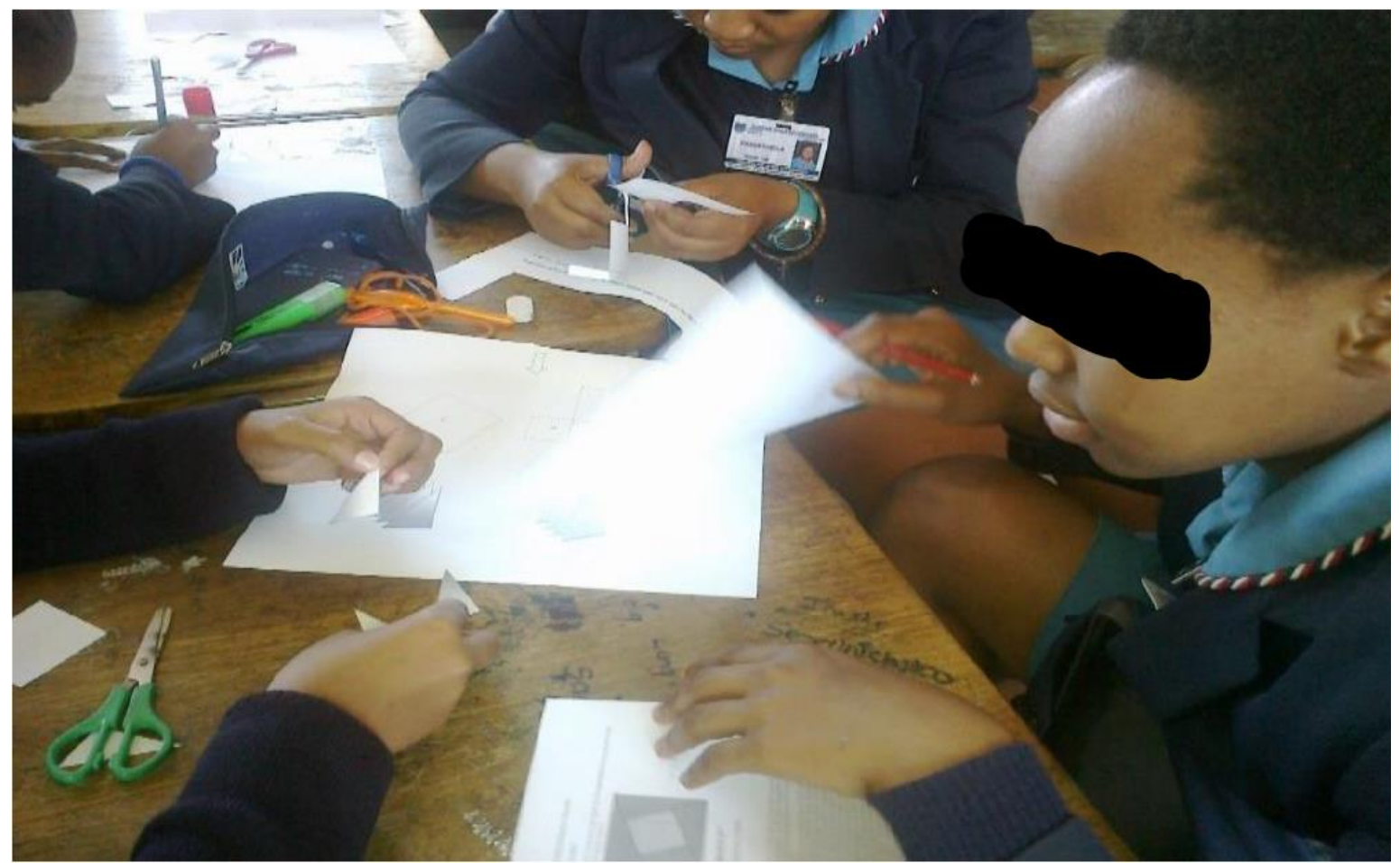

Figure 2. Learners engaged in a group cut and paste activity

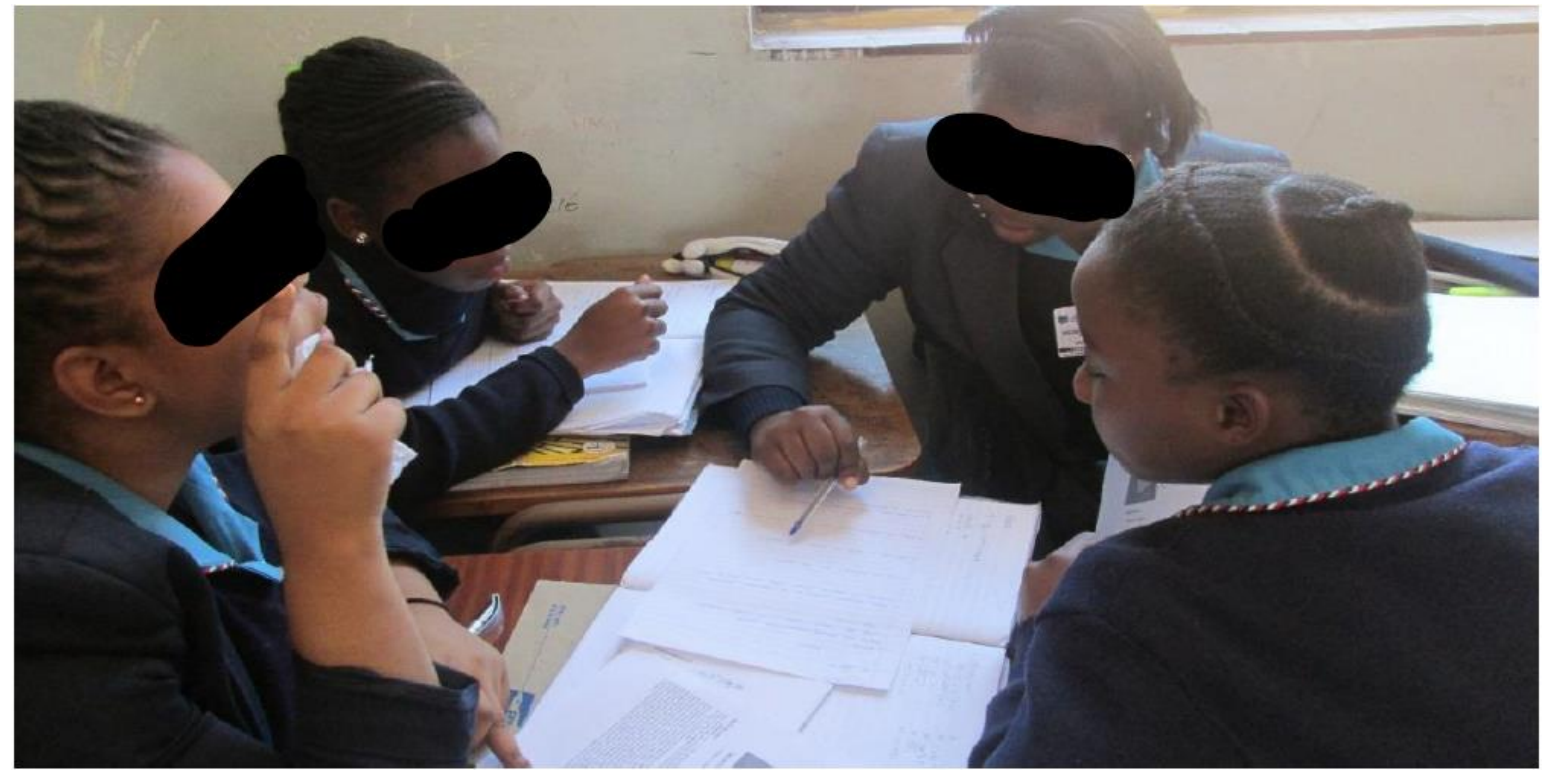

Figure 3. Learners engaged in group activities

us to understand, through sharing each other's ideas and having different perspectives on how to comprehend the questions, so, we don't just write wrong answers." (Journal Entry, $28^{\text {th }}$ of July).

The majority of learners also purported that through working in groups HOM integration afforded introverted learners the opportunity to gain confidence as they interacted with their peers. Londy captured this influence as she commented that group activities were "...fun, I could express myself very well and maybe it will help me stop being shy to answer questions. A very good way of gaining confidence in mathematics..." (Journal Entry, 28 ${ }^{\text {th }}$ of July). From learner remarks, integration of HOM created a symbiotic environment in which learners were more perceptive of the needs of their peers with a readiness to offer unsolicited assistance aimed at ensuring that all were on par with regards to curricula expectations. Such a context supported a 


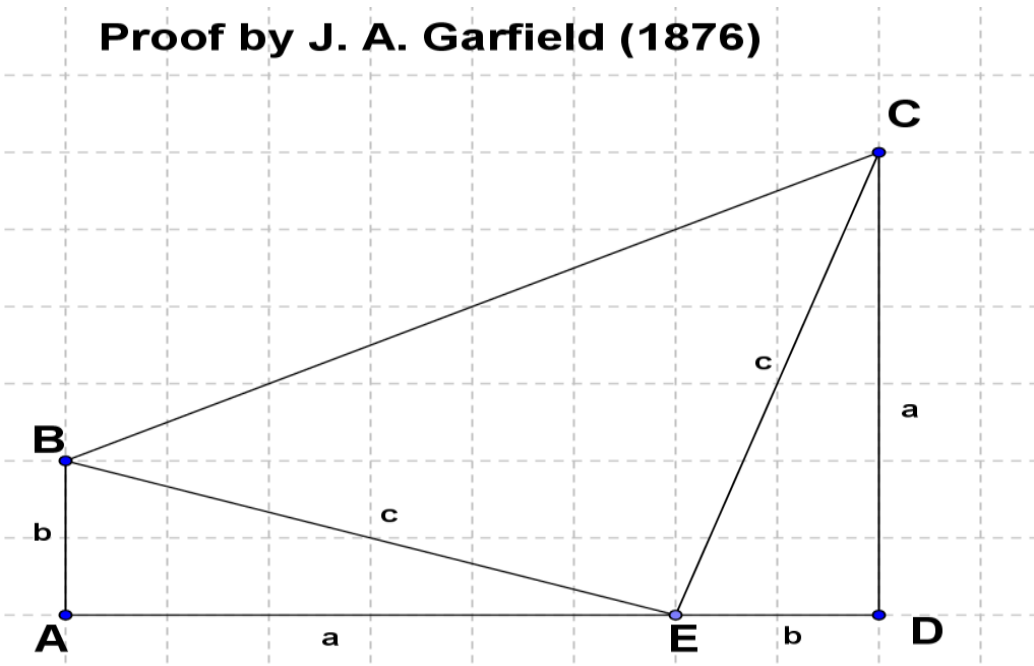

Figure 4. Proving the Pythagorean Theorem using a trapezium (using GeoGebra software)

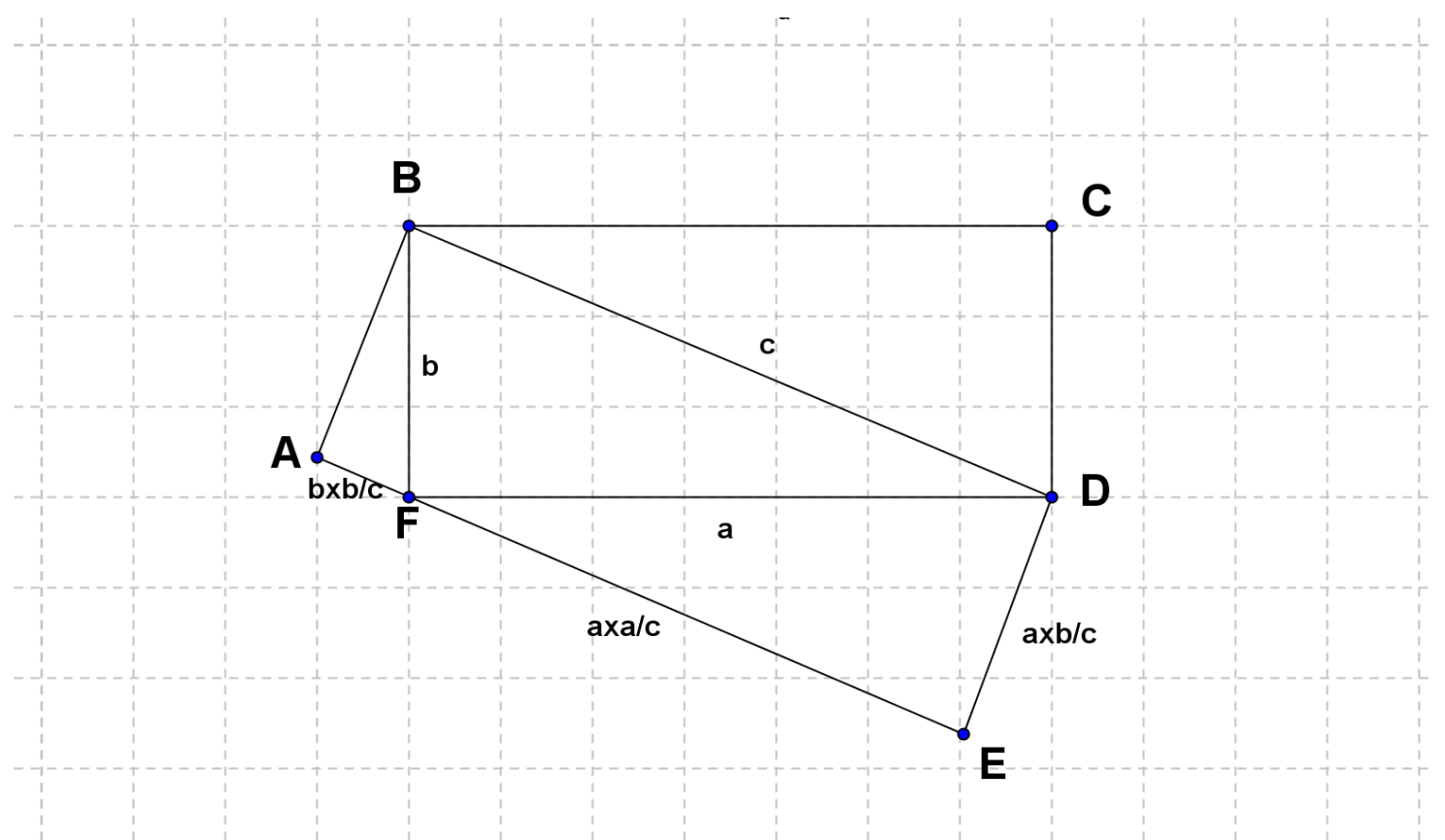

Figure 5. Proving the Pythagorean Theorem using rectangles (drawn using Geogebra software)

pedagogic setting characterised by healthy social relations and unlimited opportunities for synergistic nurturing of learner mathematical potential.

\section{Learners' Perception of HOM Integration as Technology Deployment in Teaching}

HOM through the genetic approach advocates for novel context-based approaches to teaching. In the $21^{\text {st }}$ century and heeding the clarion demands of the fourth industrial revolution HOM integration had to include technology integration. Technology had the potential to capture learners' attention and maintain learners' interest hence it had a motivating effect on the learners. Learners had lessons in which the GeoGebra application was used in expository shape drawing and proof discussions. The learners used these diagrams to re-discover the proofs, firstly using a trapezium that had been divided to form various sizes of triangles and secondly using rectangles assembled together to prove the Pythagorean Theorem. Diagrams in Figures 4 and 5 were presented to learners in the lessons in which technology was deployed while teaching and learning of the Theorem of Pythagoras Theorem and proofs. 
In spite of scholarly work, indicating learners do not enjoy working with numbers, algebraic terms and expressions (Naidoo \& Kapofu, 2020); after exposure to lessons in which HOM was integrated, most learners seemed engrossed in the lesson and its activities. When asked if the use of technology had any effect on the lesson and their view of the Theorem of Pythagoras majority of learners indicated that technology made the lessons more interesting and captivating. Ayanda's response to the question was:

\begin{abstract}
"It was an exciting method because you were not only teaching us about mathematics but giving visuals about how you can use devices like the laptop and the projector to actually make mathematics exciting apart from the daily sequences of just using the chalkboard and writing down notes and trying to figure things out. I think you gave us a perspective of things we usually don't get from mathematics..." (Group Interview, 17 th of September).
\end{abstract}

Despite learners not physically manipulating the shapes as they did in group paper cutting activities, they still regarded the use of the GeoGebra application as a way of concretising target concepts. "...we are a very lazy generation, we sit around a TV, so using the projector is a way of turning something that is a habit to us and something we usually do and make it into something that can benefit us rather than destroy us..." (Busi, Focus Group, $17^{\text {th }}$ of September). It seemed HOM integration through technology deployment had the utility in communicating mathematical ideas through the currency inherent in visualisation. This inference is premised on claims made by Phume, "Some of us like to look at things or watch, so a visual board makes an impact on our understanding of the Pythagoras' Theorem because those shapes stayed in our minds..." (Focus Group, $17^{\text {th }}$ of September). In the same focus group, Pinky added to this perspective highlighting that "...using technology to study is the best and fun way you can learn things... "It got more people to concentrate on what they were doing...in fact this maths is better than all the mathematics." (Focus Group, 17 th of September). In an epoch in which youth is synonymous with technological astuteness HOM integration through technology deployment resonates with learner realities and harnesses what most learners were brought up with and find irresistible.

\title{
CONCLUSION
}

This study sought to ascertain the influence of inclusion of the history of the Theorem of Pythagoras on learner perceptions. After the integration of HOM in their lessons even though learners still considered mathematics to be a subject that required time and concentration they seemed to consider it in appositive light. The participants now regarded hard work as an investment and enjoyed it without negativity. Through historical narratives, learners saw the mathematicians in HOM as their role models. This aspect encouraged learners to work hard in the face of adversity. After the integration of HOM, solicited learner perceptions indicated that learners now had an appreciation of the reasoning behind conducting proofs. Learners no longer regarded proofs negatively but enjoyed making their own discoveries through proving the existing Theorem of Pythagoras. In conclusion, it is important to note that after the integration of HOM learners' perceptions were that geometry was not as difficult as they had initially indicated in the first part of this project. Thus, despite challenging in mathematical tasks, learners now regarded mathematics and geometry as challenges that they needed to be confront and conquer.

\section{IMPLICATIONS FOR PRACTICE}

With regards to implications for practice, HOM is a likely vehicle for motivation and a nurturer of a sound work ethic amongst learners of mathematics. Discovery learning, an aspect of the history of mathematics assisted in development of reasoning skills, inquisitive minds and confidence in mathematics by the learners. By way of suggesting from study findings which affirm existing theoretical precepts, educators of mathematics may consider revisiting practice and begin to deviate towards collective inquiry-based pedagogic settings. Such contexts have the potential of assisting learners in developing their mathematical acumen through making their own discoveries. Implicit in this suggestion is the need for learners to continue to be presented with multiple opportunities for mathematical exploration. As they discover connections and conceptual conceptions, learners do not only get the intellectual affirmation, but also their sense of competency is conduced, which is a critical facet for intrinsic motivation.

The integration of HOM in the mathematics curriculum could have similar benefits as those established in this study. Instead of just having snippets of HOM in school textbooks, it may be worthwhile entertaining investing in the integration of HOM at policy level. Learners find it interesting to learn the history of 
mathematics but if it is not examinable educators may consider it time wasting as they focus on examinable concepts. Though we don't believe in the capacity of this work to be prescriptive it may be worthwhile making a suggestion that aspects of HOM be examinable as a worthwhile avenue for promoting HOM integration in pedagogic settings. Curriculum planners may consider the possibility of including HOM-nuanced comprehension questions and essays to cater for learners who are not good with numbers but may mostly likely to develop an affinity for numbers through historical associations. As we conclude this study we believe HOM has great yet untapped potential which may have utility in resolving the challenges of learner apathy and disengagement in mathematics classrooms.

\section{Disclosure statement}

No potential conflict of interest was reported by the authors.

\section{Notes on contributors}

Lifeas Kudakwashe Kapofu - Department of Education Australia, Australia.

Winfilda Kapofu - Durban Girls Secondary School, South Africa.

\section{REFERENCES}

Anderson, R. (2007). Being a mathematics learner: Four faces of identity. Mathematics Educator, $17(1), 1$ - 14. Babbie, E. (1990). Survey research methods (2nd ed.): Belmont, California: Wadsworth Publishing Company.

Barbin, E. (2000). Integrating history: Research perspectives. In J. Fauvel \& J. van Maanen (Ed.), History in mathematics education: An ICMI book (pp. 63 - 90). Dordrecht, Netherlands: Kluwer Academic Publishers.

Barry, D. T. (2014). Mathematics in search history. Mathematics Teacher, 93(8), 647-650.

Bidwell, J. K. (1993). Humanize your classroom with the history of mathematics. The Mathematics Teacher, 461-464.

Bogdan, R. C., \& Biklen, S. K. (1992). Qualitative research for education: An introduction to theory and methods. Needham Heights, MA: Allyn \& Bacon.

Bütüner, S. Ö., \& Baki, A. (2020). The Use of History of Mathematics in the Mathematics Classroom: An Action Study. International Journal of Education in Mathematics, Science and Technology, 8(2), 92117. https://doi.org/10.46328/ijemst.v8i2.843

Carter, P., Dunne, L., Morgan, H., \& Smuts, C. (2006). Mathematics: Grade 9 Learners' book NCS. Cape Town, South Africa: Cambridge University Press.

Clark, K. (2019, February). History and pedagogy of mathematics in mathematics education: History of the field, the potential of current examples, and directions for the future. In Eleventh Congress of the European Society for Research in Mathematics Education. Freudenthal Group; Freudenthal Institute; ERME.

Clark, K. M., Kjeldsen, T. H., Schorcht, S., \& Tzanakis, C. (2018). Mathematics, Education and History. Towards a harmonious partnership. ICME-13 monographs. Cham: Springer. https://doi.org/10.1007/978-3-319-73924-3

Cohen, L., Manion, L., \& Morrison, K. (2013). Research methods in education. London, Routledge, Taylor \& Francis Group. https://doi.org/10.4324/9780203720967

Collingwood, R. G., \& Collingwood, R. G. (1994). The idea of history. Oxford University Press on Demand.

De Villiers, M. (2008). Generalizing the Nagel line to circumscribed polygons by analogy and constructive defining. Pythagoras, Journal of AMESA, 32-40. https://doi.org/10.4102/pythagoras.v0i68.65

Denzin, N. K., \& Lincoln, Y. S. (2005). Handbook of qualitative research (3rd ed.): London, Sage Publications.

Department of Basic Education. (2010). National Curriculum Statement. Pretoria: Government Print.

Department of Basic Education. (2011). "Curriculum and Assessment Policy Statement" (CAPS).

Department of Education. (2002). Revised National Curriculum Statement (Grade $R$ - 9). Pretoria.

Department of Education. (2014). Matric Results Analysis Report (Grade 12). Pretoria. 
Department of Education. (May 2002). Revised National Curriculum Statement (RNCS) Grades R-9 (Schools): Mathematics (Vol. Gazette No.: 23406, Vol. 443). Pretoria.

Dinaledi Zenex Foundation. (2007). Putting Language into the mathematics and science equation. South Africa: Dinaledi.

Entwistle, N., \& Smith, C. (2002). Personal understanding and target understanding: Mapping influences on the outcomes of learning. British Journal of Educational Psychology, 72(3), 321-342. https://doi.org/10.1348/000709902320634528

Eves, H. W. (1976). An introduction to the history of mathematics.

Felder, R. M., \& Brent, R. (2007). Cooperative learning, Education designs. In P. A. Mabrouk (Ed.), Active learning: Models from analytical sciences (pp. 35 - 53). Washington DC: American Chemical society. https://doi.org/10.1021/bk-2007-0970.ch004

Fox, N., Hunn, A., \& Mathers, N. (2002). Sampling, Trent Focus Group.

Freudenthal, H. (2006). Revisiting mathematics education: China lectures (Vol. 9). Springer Science \& Business Media.

Fried, M. N., Guillemette, D., \& Jahnke, H. N. (2016, July). Theoretical and/or conceptual frameworks for integrating history in mathematics education.

Furinghetti, F. (2000). The history of mathematics as a coupling link between secondary and university teaching: International Journal of Mathematics Education in Science and Technology, 31(1), 43-51. https://doi.org/10.1080/002073900287372

Furinghetti, F. (2007). Teacher education through the history of mathematics. Educational Studies in Mathematics, 66(2), 131-143. https://doi.org/10.1007/s10649-006-9070-0

Furinghetti, F., \& Radford, L. (2002). Historical conceptual developments and the teaching of mathematics: from philogenesis and ontogenesis theory to classroom practice. In Handbook of international research in mathematics education (pp. 643-666). Routledge.

Goktepe, S., \& Ozdemir, A. S. (2013). An example of using history of mathematics in classes. European Journal of Science and Mathematics Education, 1(3), 125-136.

González, G., \& Herbst, P. G. (2006). Competing arguments for the geometry course: Why were American high school students supposed to study geometry in the twentieth century? International Journal for the History of Mathematics Education, 1(1), 7-33.

Hanna, G. (1998). Proof as explanation in geometry. Focus on learning problems in mathematics, 20, 4-13.

Hartley, M. S., \& Treagust, D. F. (2014). Learner perceptions of the introduction of computer-assisted learning in mathematics at a peri-urban school in South Africa. Learning Environments Research, 17(1), 95-111. https://doi.org/10.1007/s10984-014-9157-y

Horton, L. B., \& Panasuk, R. M. (2013). Integrating History of Mathematics into the Classroom: Was Aristotle wrong?, 1927-2677. Retrieved from www.sciedu.ca/jct website.

Hoyrup, J. (1994). In measure, number, and weight, Studies in mathematics and culture. SUNY Press.

Jankvist, U. T. (2009). History of modern applied mathematics in mathematics education. For the learning of mathematics, 29(1), 8-13.

Kaplan, B., \& Maxwell, J. A. (1994). Qualitative research methods for evaluating computer information systems. In J. G. Anderson, C. E. Anderson, \& S. J. Jay, (Eds.), Evaluating health care information systems: Method and application. California: Sage Publications.

Karp, A. (2014). The history of mathematics education: Developing a research methodology. In Handbook on the history of mathematics education (pp. 9-24). Springer, New York, NY. https://doi.org/10.1007/978-14614-9155-2_2

Kilpatrick, J. (2020). History of research in mathematics education. Encyclopedia of mathematics education, 349-354. https://doi.org/10.1007/978-3-030-15789-0_71

Kraak, A. (2015). The National Skills Development Strategy: a new institutional regime for skills formation in post-apartheid South Africa.

Laridon, P. (2006). Classroom Mathematics: Grade 8 Learners'book. Sandton, SA Heinemann Publishers (Pty) Ltd. 
Moretti, V., \& Radford, L. (2016, July). Towards a culturally meaningful history of concepts and the organization of mathematics teaching activity. In Radford, L., Furinghetti, F., \& Hausberger, T. (Eds.), Proceedings of the 2016 ICME Satellite Meeting of the International Study Group on the Relations Between the History and Pedagogy of Mathematics (pp. 503-512). Montpellier, France: IREM de Montpellier.

Naidoo, J., \& Kapofu, W. (2020). Exploring female learners' perceptions of learning geometry in mathematics. South African Journal of Education, 40(1), 1-11. https://doi.org/10.15700/saje.v40n1a1727

Pehkonen, E., \& Torner, G. (1998). The state of the art in mathematics-related belief research: Results of the MAVI activities. Helsinki, Finland: University of Helsinki.

Polya, G. (1963). Studies in Mathematics. Stanford. School Mathematics Groups.

Radebe, K. (2013). Beyond Matric Results, the deeper picture. Johannesburg, Gauteng, South Africa. Retrieved from http://www.moneyweb.co.za/moneyweb-SouthAfrica

Radford, L. (2015). Of love, frustrations and mathematics: A cultural-historical approach to emotions in mathematics teaching and learning. In B. Pepin, \& B. Roesken-Winter (Eds.). From beliefs to dynamic affect systems in mathematics education: Advances in mathematics education (pp. 25 - 49). Manchester: Springer International Publishing.

Radford, L., Furinghetti, F., \& Katz, V. (2007). Introduction The topos of meaning or the encounter between past and present. Educational Studies in Mathematics, 66(2), 107-110. https://doi.org/10.1007/s10649006-9076-7

Schoenfeld, A. H. (1992). Learning to think mathematically: Problem solving, metacognition and sense making in mathematics. In D. A. Grouws (Ed.), Handbook of research on mathematics teaching and learning (pp. 334 - 370). New York: Macmillan.

Schwandt, T. A. (2002). Three epistemological stances for qualitative inquiry. In N. K. Denzin \& Y. S. Lincoln (Eds.), Handbook of qualitative research (3rd ed.): London, Sage Publications.

Sinclair, N., \& Bruce, C. D. (2015). New opportunities in geometry education at the primary school. ZDM, 47(3), 319-329. https://doi.org/10.1007/s11858-015-0693-4

Siu, M. K. (2004). History and pedagogy of mathematics: No, I do not use history of mathematics in my class. Why? Paper presented at the Proceedings of HPM Upsalla.

Siu, M. K., \& Tzanakis, C. (2004). History of mathematics in classroom teaching-appetizer? Main course? Or dessert. Mediterranean Journal for Research in Mathematics Education, 3(1-2), v-x.

Torerai, E. (2013, 06 Dec.). Results disappointed us, The New Age. Retrieved from http://www.thenewage.co.za/mobi/Detail.aspx?NewsID=73094\&Cat=1017

Van de Walle, J. A. (2004). Elementary and Middle School Mathematics: Teaching developmentally. Boston: Pearson.

Wong, K. Y. (2004). Add Cultural Values to Mathematics Instruction. Singapore: National Institute of Education.

Yin, R. (2017). Case Study Research: Design and Method. Newbury Park, CA: Sage Publications. 